\title{
Revisiting the Predictive Power of Thinking Styles for Academic Performance
}

\author{
LI-FANG ZHANG \\ Faculty of Education \\ The University of Hong Kong
}

\begin{abstract}
The present study is a further examination of the contributions of thinking styles to academic achievement (see L-F. Zhang, 2001a, 200lb, 2002f; L-F. Zhang \& R. J. Sternberg, 1998). Secondary school students in Hong Kong $(N=250 ; 131$ from a Catholic boys' school and 119 from a Protestant girls' school) participated in the study. Students' scores on the Thinking Styles Inventory (R. J. Sternberg \& R. K. Wagner, 1992) were used to predict their academic achievement in 16 subjects after age, gender, school class level, and performance on the Sternberg Triarchic Abilities Test (R. J. Sternberg, 1993) were controlled. Results indicated that the use of the hierarchical thinking style significantly contributed to better achievement in the social sciences and humanities and that the use of the judicial style uniquely contributed to better achievement in the natural sciences. The use of the monarchic thinking style significantly predicted students' achievement in design and technology. The results of this study suggest that thinking styles should be taken into account in school settings and that thinking styles that generate creativity should be cultivated in students.
\end{abstract}

Key words: abilities, academic achievement, thinking styles

A STUDENT'S ABILITY LEVEL has been established as one of the major predictors in academic performance (Carroll, 1993; Guilford, 1967; Horn, 1994; Spearman, 1927; Sternberg, 1985, 1988; Thurstone, 1938). Yet, ability does not predict academic performance completely (Sternberg \& Williams, 1997). Indeed, the role of nonacademic factors in academic performance has also been investigated by many scholars. These factors vary from motivation and approaches to learning (Dev, 1997; Horn, Bruning, Schraw, \& Curry, 1993) to the "self" related concepts such as self-concept, self-confidence, and self-esteem (Allen, 1992;

I am grateful to the Wu Jieh-Yee Education Research Fund as administered by The University of Hong Kong for supporting this research. My very special thanks go to all the research participants.

Address correspondence to Li-fang Zhang, Faculty of Education, The University of Hong Kong, Pokfulam Road, Hong Kong; lfzhang@hkucc.hku.hk (e-mail). 
Fuertes, Sadlacek, \& Liu, 1994; Kwok \& Lytton, 1996; Mboya, 1993) and to home and family support (Chen, Lee, \& Stevenson, 1996; Cutrona, Cole, Colangelo, Assouline, \& Russell, 1994).

Style, as an individual-difference variable in academic performance, has also been the focus of many researchers (Drysdale, Ross, \& Schulz, 2001; Kim \& Michael, 1995; Nagle \& Thwaite, 1979; Pendleton, 1975; Riding \& Caine, 1993; Saracho, 1984; Yeatts \& Strag, 1971). In the study of styles, many theoretical models have been postulated since the late 1950s and early 1970s.

In the past 2 decades or so, a few major efforts have been made to conceptually integrate these stylistic models. Among these works, four major integrative models of styles stand out in the literature. The first is Curry's (1983) three-layer "onion" model. Curry proposed that nine of the major learning style measures be organized into three "strata resembling layers of an onion" (p. 7). According to this organization of learning style measures, "learning behavior is fundamentally controlled by the central personality dimensions, translated through middle strata information processing dimensions and given a final twist by interaction with environmental factors endorsed in the outer strata" (p. 7).

The second is Miller's (1987) model of cognitive processes and styles. Miller viewed cognitive styles as individual differences in the various subcomponents of an information-processing model of three main cognitive processes: perception, memory, and thought. He contended that "all of the cognitive styles are subordinate to, and reflect, a broad superordinate stylistic (analytic-holistic) difference" (p. 253).

The third is Riding and Cheema's (1991) integrative model of cognitive styles. After examining over 30 style labels in the literature based on the descriptions, correlations, methods of assessment, and effects on behavior of these style labels, Riding and Cheema concluded that they could be grouped into two principal cognitive styles: wholist-analytic and verbal-imagery. The former concerns whether an individual tends to process information in wholes or in parts; the latter pertains to whether an individual has a tendency to represent information while thinking verbally or one does so in mental pictures.

The final and most recent endeavor in integrating works on styles is Sternberg's (1997) model. According to Sternberg, works on styles fall into one of the three traditions: cognition centered, personality centered, and activity centered. Styles in the cognition-centered tradition most closely resemble abilities. Moreover, like abilities, styles in this tradition are measured by tests of maximal performance with "right" and "wrong" answers. Within this tradition, two models of styles have aroused the most interest: Witkin's (1962) field-dependence-independence model and Kagan's (1976) reflectivity-impulsivity model.

The personality-centered tradition considers styles as most closely resembling personality traits. Furthermore, like personality traits, styles in this tradition are measured by tests of typical, rather than maximal, performance. Major work in this tradition has been done by Myers and McCaulley (1988) based on 
Jung's (1923) theory of personality types. Holland's $(1973,1994)$ theory of vocational types and Gregorc's (1979) model of types of styles also fall into this tradition.

The activity-centered tradition focuses on the notion of styles as mediators of various forms of activities that tend to arise from aspects of both cognition and personality. One major group of works in this tradition is represented by similar theories of deep- and surface-learning approaches proposed by Marton (1976), Biggs (1978), Entwistle (1981), and Schmeck (1983). Moreover, Renzulli and Smith (1978) proposed different learning styles, with each corresponding to a method of teaching such as discussion, drill and recitation, and lecturing.

Aside from encompassing a variety of theoretical models of styles, the style literature also contains many style labels, including cognitive styles, learning styles, and thinking styles. These styles, although different, share one important commonality: styles are not abilities, but rather they are people's preferred ways of processing information and of using the abilities that they already have.

\section{Thinking Styles}

Sternberg's theory of thinking styles-the theory of mental self-government-was first published in 1988. Using the word "government" metaphorically, Sternberg $(1988,1997)$ proposed that just as there are many ways of governing a society, there are many ways of using the abilities that we have. These different ways of using abilities can be construed as our thinking styles. In using our abilities, we choose styles with which we feel comfortable. Moreover, people use different thinking styles on the basis of the stylistic demands of a given situation. Many characteristics of thinking styles have been delineated by Sternberg (1997), among which the modifiability of thinking styles is one of the most important. Sternberg contended that thinking styles are at least partially socialized, indicating that they can be cultivated and modified.

The theory of mental self-government delineates 13 thinking styles that fall along five dimensions of mental self-government:

1. functions (containing the legislative, executive, and judicial styles);

2. forms (containing the hierarchical, monarchic, oligarchic, and anarchic styles);

3. levels (containing the global and local styles);

4. scopes (containing the internal and external styles); and

5. leanings (containing the liberal and conservative styles).

Each of the 13 styles is briefly described in the Appendix.

The theory of mental self-government has been operationalized through a number of instruments, including the most frequently used Thinking Styles Inventory (Sternberg \& Wagner, 1992). The internal validity of the theory has been demonstrated in many studies (e.g., Bernardo, Zhang, \& Callueng, 2002; 
Cano-Garcia \& Hughes, 2000; Dai \& Feldhusen, 1999; Zhang, 1999, 2001d; Zhang \& Sternberg, 1998) conducted among students and teachers from a number of cultural groups, including Hong Kong, mainland China, the Philippines, Spain, and the United States.

The external validity of the theory has been obtained by examining the nature of thinking styles not only against a number of constructs that belong to the family of styles, but also against a few constructs that are perceived to be significantly correlated with the thinking style construct. With regard to the former, the thinking style construct has been examined with the learning approach construct defined by Biggs (1978, 1992; see Zhang, 2000b; Zhang \& Sternberg, 2000 ), the vocational interest-personality type construct postulated by Holland (1973, 1994; see Zhang, 2000a, 2001c), and the style of thinking and learning construct put forward by Torrance, McCarthy, and Kolesinski (1988; see Zhang $2002 \mathrm{e}, 2002 \mathrm{f}$ ).

With regard to the latter, the thinking style construct has been tested against the Big Five personality traits (Costa \& McCrae, 1992; see Zhang, 2002a, 2002c; Zhang \& Huang, 2001), the cognitive development construct proposed by Perry (1970, 1981, 1999; see Zhang 2002d), the self-esteem construct as defined by Coopersmith (1981; see Zhang, 2001d; Zhang \& Postiglione, 2001), and the psychosocial development construct as represented by the development of purposefulness in three aspects: vocational interest, avocational interest, and style of life (Chickering, 1969; Chickering \& Reisser, 1993; see Zhang, 2002b).

Meanwhile, researchers' interest in identifying the contributions of thinking styles to students' academic performance has never ceased, mainly because of the fact, I believe, that the emergence of theories of styles was deeply rooted in the need for explaining students' individual differences in academic performance that are beyond the explanation of their abilities. To investigate the contributions of thinking styles to achievement, a series of studies has been conducted in the aforementioned five cultural groups: Hong Kong, mainland China, the Philippines, Spain, and the United States.

The earliest investigation into the contribution of thinking styles (as defined by the theory of mental self-government) to academic achievement was conducted by Sternberg and Grigorenko (1993, also see Grigorenko \& Sternberg, 1997) among two groups of identified gifted children participating in the Yale Summer School Program. The authors found that whereas the judicial and legislative thinking styles contributed positively to a student's success in a variety of academic tasks, the executive thinking style tended to contribute negatively to success in these tasks.

A more recent study of the predictive power of thinking styles for academic achievement was conducted by Zhang (2002f), whose research participants were U.S. university students. Results from this study revealed that the conservative style positively predicted students' grade point averages, whereas the global and liberal styles negatively did so. 
In Hong Kong, three such studies (Zhang, 2001a, 2001b; Zhang \& Sternberg, 1998) have been carried out. Whereas one of the three studies (Zhang, 2001a) was conducted among school children, the remaining two had university student participants. Results from all three studies suggested the following relationships between thinking styles and academic achievement. That is, in general, thinking styles that require conformity (conservative), respect for authority (executive), and a sense of order (hierarchical) were positively related to academic achievement. Thinking styles that are creativity generating (legislative and liberal styles) tended to contribute negatively to academic achievement. Furthermore, a preference for working individually (internal style) was positively correlated with academic achievement, whereas a preference for working in groups (external style) was negatively associated with academic achievement. Finally, mixed findings were obtained for the judicial style, which demonstrated a positive effect on achievement among secondary school students and male university students but had a negative effect on achievement among female university students.

One of the Hong Kong studies involved the investigation of the contribution of thinking styles to academic achievement among university students in mainland China (Zhang, 2001b). Results indicated that, as among the American school students, the executive thinking style contributed positively to students' academic achievement scores.

In studying the contribution of thinking styles to academic achievement among Filipino university students, Bernardo et al. (2002) obtained results that were consistent with those obtained in the studies of Hong Kong students. That is, in general, thinking styles that require conformity, respect for authority, and a sense of order were positively correlated with academic achievement. The judicial style was positively related to academic achievement among Filipino students.

Finally, the investigation of the relationships of thinking styles to academic achievement has also been conducted among university students in Spain (Cano-Garcia \& Hughes, 2000). Findings from this study also supported those obtained in Hong Kong. That is, the higher academic achievers tended to be those who preferred to adhere to existing rules and procedures (executive style), who preferred to work individually (internal style), and who preferred not to create, formulate, and plan for problem solutions (legislative style in a negative sense).

To summarize, all existing studies have indicated that thinking styles significantly contribute to academic achievement. Furthermore, there is much similarity in the specific ways in which thinking styles predict academic achievement across the different cultural groups. With the exception of the studies of U.S. gifted children (the findings among the gifted children in the Yale Summer School Program were directly opposite) and the mainland Chinese university sample, the studies of all the other samples indicated that the executive, conservative, and 
monarchic styles (styles that denote conformity and rule adherence) as well as the hierarchical style (a style that communicates a sense of order) contributed positively to academic achievement, whereas the legislative and liberal styles (styles that are creativity generating) contributed negatively to academic achievement. Finally, the judicial style has been proven to have positively contributed to academic achievement among all students except among Hong Kong university female students.

There are three issues that give rise to the need for further research on the relationships between thinking styles and academic achievement. First, the majority of the studies used average achievement scores rather than achievement scores in specific subject areas. However, given that thinking styles are at least partially socialized, success in achieving high scores for one subject (e.g., mathematics) could be different from that for another subject (e.g., history). Therefore, in the present study I used students' academic scores in specific subjects.

Second, given that one of the major motivations for constructing theories of styles was to allow the examination of the contributions of styles over and above abilities, controlling research participants' abilities becomes critical in the study of the contribution of styles to academic achievement. However, among the existing studies, only the two (Grigorenko \& Sternberg, 1997; Sternberg \& Grigorenko, 1993) of gifted children have controlled students' performance on an ability test. Zhang and her colleagues' studies of Hong Kong and mainland Chinese students, students in the Philippines, and their study of American university students merely controlled students' self-rated abilities. Although self-rating possesses a good amount of reliability and validity, the results from self-rated measures do not always correspond to results from performance measures. Consequently, in the present study I take into account students' abilities as measured by a performance test.

Finally, previous findings have been mixed regarding the effects of student characteristics (such as age, gender, and school class level) on thinking styles (e.g., Sternberg \& Grigorenko, 1995; Zhang, 1999, 2001a, 2001d; Zhang \& Postiglione, 2001; Zhang \& Sachs, 1997). However, none of the existing studies have taken these student characteristics into account. A preliminary analysis of the present data resulted in significant differences in thinking styles based on age, gender, and school class level. For example, older students tended to be less local, hierarchical, and external, but more internal in their thinking styles than did their younger counterparts. Female students tended to be less legislative, liberal, monarchic, and internal in their thinking styles than did their male counterparts. Students in higher level classes tended to be less local and hierarchical and more internal in their thinking styles than did students of lower school class levels. Thus, in the present study, students' ages, gender, and school class level were controlled.

My primary goal in this study was to identify the unique contributions of students' thinking styles to their academic achievement beyond age, gender, school 
class level, or ability. An equally important goal was to investigate the relationships between thinking styles and ability.

Based on the results of previous studies (see the above review of studies of thinking styles and academic achievement), I predicted that even after age, gender, class level, and ability are taken into account, a student's thinking style will still contribute to his or her academic scores. I also predicted that thinking style and ability are largely independent of each other.

\section{Method}

\section{Participants}

In Hong Kong, secondary schools are classified into five bands; the top $20 \%$ of primary school graduates are admitted to Band 1 secondary schools on the basis of their academic achievement (see Yung, 1997 for details). Students from two Band 1 secondary schools participated in the study. The first was a Catholic boys' school $(N=131)$, and the second was a Protestant girls' school $(N=119)$. Of all the participants, 85 were studying in Form 1 (Grade 7), 83 in Form 2 (Grade 8), and 82 in Form 3 (Grade 9). The participants ranged in age from 11 to 16 years old, with an average age of 13.6 years.

In a previous study, I (Zhang, 2001a) investigated the contributions of thinking styles to academic achievement among Form 4 (Grade 10) and Form 5 (Grade 11) school children in Hong Kong. The present study is a natural extension of the previous study because it was conducted among Form 1, Form 2, and Form 3 children.

\section{Measures}

All the students responded to two questionnaires: The Thinking Styles Inventory (TSI; Sternberg \& Wagner, 1992) and the Sternberg Triarchic Abilities Test (STAT; Sternberg, 1993). The TSI is a self-report test consisting of 65 statements, each 5 statements assessing one of the 13 thinking styles delineated in the theory of mental self-government. Each statement is rated on a 7-point Likert-type scale ranging from 1 to 7 , with 1 indicating that the statement does not at all describe the way the participants normally carry out their tasks and 7 denoting that the statement characterizes extremely well the way they normally carry out their tasks. In the present study, the participants responded to a Chinese version of the inventory that was translated and back-translated between Chinese and English in 1996.

Both the English and the Chinese versions of the TSI have obtained reasonably good reliability as well as good internal and external validity (see earlier discussion). The Cronbach alphas usually have ranged from the mid .50s to the low $.80 \mathrm{~s}$. Occasionally, the alpha coefficients for the local, monarchic, and anarchic styles fall below .50. In the present study, the Cronbach alphas ranged from .46 
(anarchic style) to .82 (liberal style), with the median being .70 (conservative style). Detailed statistics on the thinking style scales are presented in Table 1.

The STAT (Sternberg, 1993) is a performance test that assesses the analytical, creative, and practical abilities proposed in Sternberg's (1985) triarchic theory of human intelligence. Level $\mathrm{H}$ of the STAT, used in the present study, was designed for secondary school and university students. Furthermore, the test measures performance in three domains-verbal, quantitative, and figural. The use of a variety of domains, according to Sternberg (1999), was intended to ensure that students who do well on one particular form of representation but not on another will nonetheless be provided with the opportunity to show their abilities.

The multiple-choice test contains 36 items; each 9 items contribute to the assessment of each of the three ability scales: Analytical, Creative, and Practical. The nine items in each kind of ability, in turn, are divided into the three domains: verbal, quantitative, and figural. Thus, the 36 items are distributed among 9 subscales ( 3 kinds of abilities by 3 domains). These nine subscales are Analytical-Verbal (dealing with artificial words), Analytical-Quantitative (number series), Analytical-Figural (matrices), Practical-Verbal (everyday reasoning), Practical-Quantitative (everyday math), Practical-Figural (route planning), Creative-Verbal (novel analogies), Creative-Quantitative (novel number operations), and Creative-Figural (novel series completions). Refer to Sternberg (1999) for more details.

The STAT is a research inventory that is still in the experimental stages of development (Sternberg, Castejón, Prieto, Hautamäki, \& Grigorenko, 2001). However, several studies using this inventory have supported the reliability and

TABLE 1. Thinking Style Scales $(N=250)$

\begin{tabular}{lrrr}
\hline \hline Style & $M$ & $S D$ & $\alpha$ \\
\hline Legislative & 4.90 & .89 & .71 \\
Executive & 4.55 & .87 & .61 \\
Judicial & 4.42 & .99 & .75 \\
Global & 4.02 & .80 & .49 \\
Local & 4.23 & .81 & .47 \\
Liberal & 4.51 & 1.13 & .82 \\
Conservative & 4.03 & .96 & .70 \\
Hierarchical & 4.59 & 1.01 & .77 \\
Monarchic & 4.61 & .85 & .52 \\
Oligarchic & 4.63 & .88 & .64 \\
Anarchic & 4.46 & .80 & .46 \\
Internal & 3.73 & 1.17 & .80 \\
External & 4.99 & 1.03 & .74 \\
& & & \\
\hline
\end{tabular}


validity of the STAT for assessing the triarchic abilities among students in several cultures, including Finland, Spain, and the United States (e.g., Grigorenko \& Sternberg, 1997; Sternberg, 1999; Sternberg, Grigorenko, Ferrari, \& Clinkenbeard, 1999; Sternberg et al., 2001). The present study used a Chinese version of the inventory that was translated and back-translated between Chinese and English particularly for this study.

Cronbach alphas for this study were $.60, .34$, and .66 , respectively, for the Analytical, Practical, and Creative ability scales. Whereas the reliability data for the Analytical and Creative scales are considered acceptable, the reliability for the three practical subscales was too low to allow further data analyses. This low reliability might be due to inaccurate translation of some of the items. Further examination and testing of items in the Practical Scale need to be conducted among Hong Kong secondary school students. In the remaining analyses, only the analytical and creative subscales are included.

Finally, across the three school class levels, students' achievement scores in the following 16 subjects were used: art and design, biology, Chinese history, Chinese language, chemistry, computer literacy, design and technology, economics and public affairs, English, geography, history, integrated science, mathematics, music, physics, and religious studies.

\section{Data Analysis}

To achieve the objectives of the study, I conducted the following statistical procedures. First, I calculated partial correlations between the thinking style scales and the ability (only analytical and creative) scales, controlling for age, gender, and school class level. The aim of this statistical operation was to test whether or not thinking styles and abilities are independent of each other.

Second, I calculated partial correlations between students' scores on the STAT analytical and creative scales and their academic performance in various subject matters, again, controlling for age, gender, and school class level. The aim of this statistical procedure was to identify whether ability was related to students' academic performance. If so, ability needed to be controlled when examining the unique contribution of thinking styles to academic achievement. Of the 16 subjects examined, students' achievements in 10 areas were related to both analytical and creative abilities. Students' achievements in a further 5 subjects were related to creative ability. Thus, analytical and creative abilities were taken into account in the investigation of the contributions of thinking styles to academic achievement.

Finally, I conducted hierarchical multiple-regression procedures with students' academic performance as the dependent variables and the thinking styles as the independent variables, controlling for age, gender, school class level, as well as analytical and creative abilities. 


\section{Results}

Results from calculating the partial correlations between thinking styles and ability, controlling for students' age, gender, and school class level, indicated that among the partial correlation coefficients among the 13 thinking style scales and the 2 ability scales, only 2 coefficients were statistically significant. The first was between the local style and analytical ability $(r=.15, p<.05)$. The second was between the anarchic style and creative ability $(r=.18, p<.05)$. Therefore, essentially, there was a lack of relationship between ability and thinking styles, suggesting that the two constructs are largely orthogonal to each other.

Controlling for age, gender, and school class level, partial correlation coefficients suggested that 10 of the 16 subjects examined were significantly correlated with both analytical and creative abilities. Moreover, students' academic performance in another 5 subjects was significantly correlated with creative ability. Students' academic achievement in music was not related either to analytical ability or to creative ability. Results of this partial correlation analysis are shown in Table 2.

Table 3 contains summary statistics generated from hierarchical multipleregression procedures using the thinking styles as predictor variables for stu-

TABLE 2. Partial Correlation Coefficients Between Abilities and Achievement: Controlling for Age, Gender, and School Class Level $(N=\mathbf{2 5 0})$

\begin{tabular}{|c|c|c|}
\hline \multirow[b]{2}{*}{ Subject } & \multicolumn{2}{|c|}{ Ability scale } \\
\hline & Analytic & Creative \\
\hline Art and design & .13 & $.20 * *$ \\
\hline Biology & .08 & $.31 * *$ \\
\hline Chinese history & $.17 * *$ & $22 * *$ \\
\hline Chinese language & $.21 * *$ & $.30^{* * *}$ \\
\hline Chemistry & .13 & $.31^{* *}$ \\
\hline Computer literacy & $.18 * *$ & $.21 * *$ \\
\hline Design and technology & $.23^{*}$ & $.39 * * *$ \\
\hline Economics and public affairs & $.20 * *$ & $.27 * * *$ \\
\hline English & .10 & $.31 * * *$ \\
\hline Geography & $.25 * * *$ & $.29 * * *$ \\
\hline History & $.16^{*}$ & $.19^{* *}$ \\
\hline Integrated science & $.25 * *$ & $40^{* * *}$ \\
\hline Mathematics & $.30 * * *$ & $.35 * * *$ \\
\hline Music & .11 & .09 \\
\hline Physics & .14 & $.35 * *$ \\
\hline Religious studies & $.16^{*}$ & $.21 * *$ \\
\hline
\end{tabular}




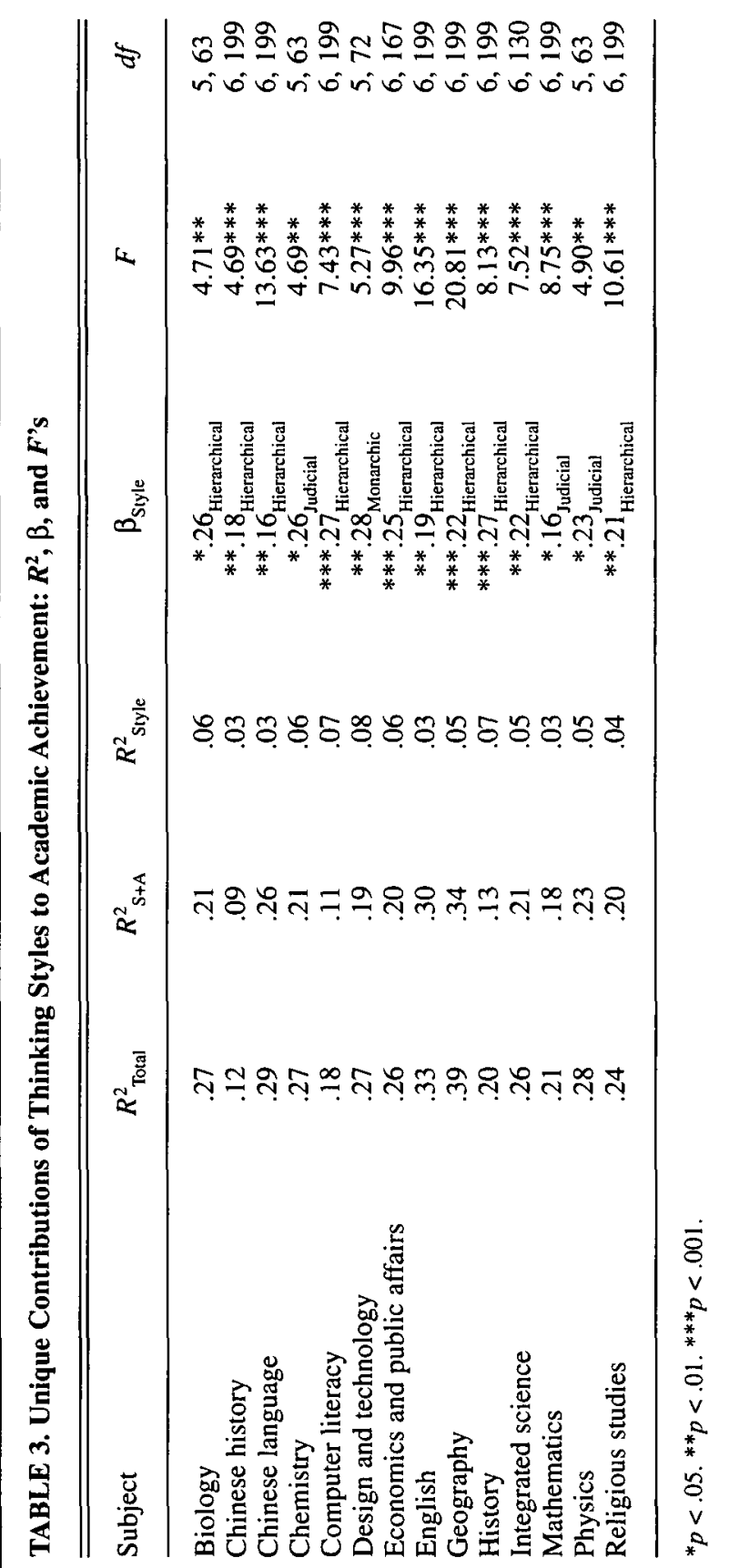


dents' academic achievement scores after controlling for age, gender, school class level, and ability scores. Among other information, the table shows the variance accounted for by student characteristics and abilities together $\left(R^{2}{ }_{\mathrm{S}+\mathrm{A}}\right)$, the total variance explained by thinking styles as well as by student characteristics and abilities $\left(R_{\text {Total }}^{2}\right)$, and the variance uniquely contributed by thinking styles $\left(R_{\text {Style }}^{2}\right)$.

Results indicated that thinking styles made unique contributions to the prediction of students' academic achievement in 14 of the 16 subjects. The two subjects to which thinking styles did not make a unique contribution were music and arts and design. The particular styles that statistically predicted achievement beyond student characteristics and abilities were the hierarchical style, the judicial style, and the monarchic style. Among these three styles, the hierarchical style stood out the most as it significantly predicted students' academic achievement scores in 10 subjects: biology, the Chinese language, Chinese history, computer literacy, economics and public affairs, English, geography, history, integrated science, and religious studies.

The judicial style significantly predicted students' academic achievement beyond student characteristics and abilities in three subjects: chemistry, mathematics, and physics. Finally, the monarchic style significantly contributed to students' achievement in design and technology over and above what has been explained by student characteristics and abilities. These unique contributions ranged from $3 \%$ to $8 \%$.

\section{Discussion}

The primary objective of the present study was to investigate the contributions of thinking styles to academic achievement after controlling the effects of age, gender, school class level, and ability. A second goal of this study was to test the relationship (or the lack of relationship) between ability and thinking styles. Both goals were achieved, with the following major findings identified.

First, partial correlations (controlling for age, gender, and school class level) resulted in only two (out of 26) significant relationships between ability and thinking styles. Therefore, it can be concluded from this study that there is a general lack of relationship between ability and thinking styles. This general lack of association was consistent with the finding obtained by Grigorenko and Sternberg (1997) in their study of American gifted school children as well as that obtained by Sternberg and Grigorenko (1995) in their study of nongifted students in four different schools. Although the null hypothesis cannot be proved, the present finding indicates that when age, gender, and school level are controlled, students' ability patterns cannot be predicted from their thinking style patterns, or vice versa. Rather, the two constructs are essentially independent of each other.

The second major finding concerns the unique contribution of thinking styles to academic achievement. This finding warrants two points for discussion. 
A first point relates to the manner in which particular thinking styles uniquely contributed to students' academic achievement. As has been described in the Results section, three thinking styles uniquely contributed to the prediction of students' academic achievement: the hierarchical, judicial, and monarchic styles. Specifically, the hierarchical style significantly contributed to the prediction of students' academic achievement in 10 subjects. Among these 10 subjects, the majority (all except integrated science) are subjects in the fields of social science and humanities. This finding not only indicates that the hierarchical style played an important role in students' academic achievement in these fields; it can also be interpreted that the use of hierarchical thinking style in dealing with these subjects tended to be rewarded academically in the two participating schools.

The judicial style contributed to students' achievement in chemistry, mathematics, and physics. All three of these subjects are from the natural sciences discipline. This finding indicates that the judicial style played an important role in students' achievement in natural sciences subjects, but it can also be understood that the use of the judicial style in learning these subjects tended to be rewarded academically in the two participating schools. Finally, the monarchic style contributed to students' achievement in the subject of design and technology.

Consistent with other studies that used the TSI to examine the contribution of thinking styles to academic achievement (e.g., Bernardo et al., 2002; Grigorenko \& Sternberg, 1997; Sternberg \& Grigorenko, 1993; Zhang, 2001a, 2001b; Zhang \& Sternberg, 1998), results of the present study identified the unique contributions of thinking styles to students' academic achievement. Furthermore, the hierarchical style has been consistently found to contribute to the prediction of students' academic achievement in all but one study-Grigorenko and Sternberg's study of American gifted students. Students with higher scores on the hierarchical style tended to do better academically.

Another style that constantly appeared as one of the major predictors for academic achievement was the judicial style. However, the ways in which the judicial style contributed to academic achievement have been mixed. Whereas higher scores on the judicial style tended to be associated with better achievement among students in the Philippines and in the United States, as well as among Hong Kong university male students and among secondary school students, higher scores on the judicial style were related to lower achievement scores among Hong Kong university female students.

None of the existing studies, including the present study, intended to examine the domain specificity of the contributions of styles to achievement. However, the present findings have clearly revealed the domain specificity of thinking styles in their contribution to academic achievement. That is, the hierarchical style contributed to the achievement in subjects of social sciences and humanities, and the judicial style predicted students' achievement in subjects of natural sciences. Although the examination of thinking styles' domain specificity was not a major concern of the present study, the identification of this clear pattern of 
thinking styles' domain specificity warrants future research that focuses on exploring how thinking styles affect students' academic achievements in different academic disciplines.

The second point for discussion that was dictated by the finding of the unique contributions of thinking styles to academic achievement beyond student characteristics and ability is the independence of thinking styles from ability. That is, the ways in which thinking styles uniquely contributed to academic achievement reinforced the finding obtained from the partial correlations between thinking styles and ability - the finding that thinking styles and ability were independent of each other.

By definition, the analytical ability and the judicial style should reflect each other. That is, the use of analytical ability involves judicial thinking; and vice versa, the use of the judicial style requires one to be analytical. However, the ways in which the tested abilities were related to academic achievement were independent from the manners in which thinking styles predicted academic achievement. Although 10 of the 16 subjects were related to analytical ability, only 1 subject (mathematics) was significantly predicted by the judicial style. By the same token, although students' achievements in 3 subjects (chemistry, mathematics, and physics) were predicted by the judicial style, only mathematics was significantly correlated with analytical ability. Therefore, the general lack of association obtained from the partial correlations was supported by the ways in which thinking styles uniquely contributed to academic achievement.

\section{Conclusions and Implications}

Two conclusions can be drawn from the present results. First, with age, gender, and school class level being controlled, ability and thinking styles are essentially independent of each other. This implies that thinking styles and ability are two very different constructs. Yet, thinking style is as important as ability in student learning. Thus, along with other variables (especially ability) that are traditionally believed to affect student performance, thinking styles should also be taken into account in school settings.

Second, along with previous studies, the present study indicated that to be successful in academic performance in almost all educational systems, the use of hierarchical thinking style is critical. As discussed earlier, other recurrent styles that significantly predicted academic achievement in various cultures have been the judicial, conservative, executive, monarchic, and internal styles. Sadly, the consistent finding regarding the creativity generating styles has been that they either did not significantly predict or had a negative impact on students' academic achievements.

What is going on? Why is there such a lack of encouragement of creativity generating styles? Why is it that the lack of encouragement has gone to such an extreme that even the subjects that should theoretically require creative styles 
were not related to the creativity generating styles? Specifically, why was such a subject as design and technology significantly predicted by the monarchic thinking style but not by creativity generating styles such as the legislative style or liberal style? Why was it that the creativity generating styles did not matter in achievement in music, or in art and design?

A recent article (Yeung, 2003) from the South China Morning Post, Hong Kong's leading English language newspaper, seems to have provided a clear answer to such questions. Yeung reported that about one third of Hong Kong schools did not offer arts classes at the senior secondary school level and that arts subjects are often regarded as "unimportant "pastimes"" by schools and are taught by unqualified teachers. Yeung also reported that where the arts were taught, classes were often uninspiring and limited to craft, design, and music.

Apparently, there is an urgent need for Hong Kong educators and educators in other school systems in which such disturbing findings as creative thinking are either not being encouraged or are being penalized to embark on a serious endeavor to cultivate creative thinking. This urgent need is demanded for students' future career success. To be successful in the world of work, students will have to be able to use a variety of thinking styles, especially creativity generating styles.

\section{Future Research}

Whether or not thinking styles contribute to academic achievement is no longer the major issue. After a decade of research on the contributions of thinking styles to academic achievement (from Sternberg and Grigorenko's 1993 study to the present study), using the theory of mental self-government has clearly and consistently indicated that thinking styles have significant predictive power for students' academic performance. Instead, the major issue that scholars should focus on is how and why particular thinking styles contribute to students' academic achievement in some subject matters but not to that in other subject matters.

Sternberg $(1988,1997)$ argued that thinking styles are at least partially socialized. The success in different academic subjects may require different thinking styles. Thus, not unexpectedly, in the process of studying different subjects, students might have been socialized to use particular thinking styles. However, this is merely a post hoc speculation. Carefully designed investigations need to be conducted to examine the domain specificity of thinking styles with respect to their unique contributions to academic performance.

\section{REFERENCES}

Allen, W. R. (1992). The color of success: African American college student outcomes at predominantly White and historically Black public colleges and universities. Harvard 
Educational Review, 62, 26-44.

Bernardo, A. B., Zhang, L. F., \& Callueng, C. M. (2002). Thinking styles and academic achievement among Filipino students. The Journal of Genetic Psychology, 163, 149-163.

Biggs, J. B. (1978). Individual and group differences in study processes. British Journal of Educational Psychology, 48, 266-279.

Biggs, J. B. (1992). Why and how do Hong Kong students learn? Using the Learning and Study Process Questionnaires. Education Paper No. 14, Faculty of Education, The University of Hong Kong.

Cano-Garcia, F., \& Hughes, E. H. (2000). Learning and thinking styles: An analysis of their interrelationship and influence on academic achievement. Educational Psychology, 20, 413-430.

Carroll, J. B. (1993). Human cognitive abilities: A survey of factor-analytic studies. New York: Cambridge University Press.

Chen, C. S., Lee, S. Y., \& Stevenson, H. W. (1996). Long-term prediction of academic achievement of American, Chinese, and Japanese adolescents. Journal of Educational Psychology, 18, 750-759.

Chickering, A. (1969). Education and identity. San Francisco: Jossey-Bass.

Chickering, A., \& Reisser, L. (1993). Education and identity (2nd ed.). San Francisco: Jossey-Bass.

Coopersmith, S. (1981). Self-esteem inventories. Palo Alto, CA: Consulting Psychologists Press.

Costa, P. T. Jr., \& McCrae, R. R. (1992). The NEO-PI-R: Professional manual. Odessa, FL: Psychological Assessment Resources.

Curry, L. (1983). An organization of learning styles theory and constructs. ERIC Document 235, 185.

Cutrona, C. E., Cole, V., Colangelo, N., Assouline, S. G., \& Russell, D. W. (1994). Perceived parental social support and academic achievement: An attachment theory perspective. Journal of Personality and Social Psychology, 66, 369-378.

Dai, D. Y., \& Feldhusen, J. F. (1999). A validation of the thinking styles inventory: Implications for gifted education. Roeper Review, 21, 302-307.

Dev, P. C. (1997). Intrinsic motivation and academic achievement: What does their relationship imply for the classroom teacher? Remedial and Special Education, 18, 12-19.

Drysdale, M. T. B., Ross, J. L., \& Schulz, R. A. (2001). Cognitive learning styles and academic performance in 19 first-year university courses: Successful students versus students at risk. Journal of Education for Students Placed at Risk, 6, 271-289.

Entwistle, N. (1981). Styles of teaching and learning: An integrated outline of educational psychology for students, teachers, and lecturers. New York: Wiley.

Fuertes, J. N., Sedlacek, W. E., \& Liu, W. M. (1994). Using the SAT and noncognitive variables to predict the grades and retention of Asian American university students. Measurement and Evaluation in Counseling and Development, 27, 74-84.

Gregorc, A. F. (1979). Learning/teaching styles: Potent forces behind them. Educational Leadership, 36, 234-236.

Grigorenko, E. L., \& Sternberg, R. J. (1997). Styles of thinking, abilities, and academic performance. Exceptional Children, 63, 295-312.

Guilford, J. P. (1967). The nature of human intelligence. New York: McGraw-Hill.

Holland, J. L. (1973). Making vocational choices: A theory of careers. Englewood Cliffs, NJ: Prentice-Hall.

Holland, J. L. (1994). Self-directed search. Odessa, FL: Psychological Assessment Resources.

Horn, J. L. (1994). Theory of fluid and crystallized intelligence. In R. J. Sternberg (Ed.), 
The encyclopedia of human intelligence (Vol. 1, pp. 443-451). New York: Macmillan.

Horn, C., Bruning, R., Schraw, G., \& Curry, E. (1993). Paths to success in the college classroom. Contemporary Educational Psychology, 18, 464-478.

Jung, C. (1923). Psychological types. New York: Harcourt Brace.

Kagan, J. (1976). Commentary on reflective and impulsive children: Strategies of information processing underlying differences in problem solving. Monographs of the Society for Research in Child Development, 41 (No. 5, Serial No. 168).

Kim, J., \& Michael, W. B. (1995). The relationship of creativity measures to school achievement and preferred learning and thinking style in a sample of Korean high school students. Educational and Psychological Measurement, 55, 60-74.

Kwok, D. C., \& Lytton, H. (1996). Perceptions of mathematics ability versus actual mathematics performance: Canadian and Hong Kong Chinese children. British Journal of Educational Psychology, 66, 209-222.

Marton, F. (1976). What does it take to learn? Some implications on an alternative view of learning. In N. J. Entwistle (Ed.), Strategies for research and development in higher education (pp. 200-222). Amsterdam: Swets and Zeitlenger.

Mboya, M. M. (1993). Self-concept of academic ability: Relations with gender and academic achievement. Perceptual and Motor Skills, 77, 1131-1137.

Miller, A. (1987). Cognitive styles: An integrated model. Educational Psychology, 7, 251-268.

Myers, I. B., \& McCaulley, M. H. (1988). Manual: A guide to the development and use of the Myers-Briggs Type Indicator. Palo Alto, CA: Consulting Psychologists Press.

Nagle, R. J., \& Thwaite, B. C. (1979). Are learning disabled children more impulsive? Comparison of learning disabled and normal-achieving children on Kagan's Matching Familiar Figures Test. Psychology in the Schools, 16, 351-355.

Pendleton, J. K. (1975). Mathematical concept attainment of sixth grade students in relation to their cognitive styles. Southern Journal of Educational Research, 9, 168-178.

Perry, W. G. (1970). Forms of intellectual and ethical development in the college years: A scheme (2nd ed.). New York: Holt, Rinehart and Winston.

Perry, W. G. (1981). Cognitive and ethical growth: The making of meaning. In A. Chickering (Ed.), The modern American college (pp. 76-116). San Francisco: Jossey-Bass.

Perry, W. G. (1999). Forms of intellectual and ethical development in the college years: A scheme. (3rd ed.). San Francisco: Jossey-Bass.

Renzulli, J. S., \& Smith, L. H. (1978). Learning Styles Inventory. Mansfield Center, CT: Creative Learning Press.

Riding, R. J., \& Caine, T. (1993). Cognitive style and GCSE performance in mathematics, English language and French. Educational Psychology, 13, 59-67.

Riding, R. J., \& Cheema, I. (1991). Cognitive styles-An overview and integration. Educational Psychology, 11(3 \& 4), 193-215.

Saracho, O. N. (1984). Young children's academic achievement as a function of their cognitive styles. Journal of Research and Development in Education, 18, 44-50.

Schmeck, R. R. (1983). Learning style of college students. In R. F. Dillon \& R. R. Schmeck (Eds.), Individual differences in cognition (Vol. 1, pp. 233-279). San Diego, CA: Academic Press.

Spearman, C. (1927). The abilities of man. New York: Macmillan.

Sternberg, R. J. (1985). Beyond IQ: A triarchic theory of human intelligence. New York: Cambridge University Press.

Sternberg, R. J. (1988). Mental self-government: A theory of intellectual styles and their development. Human Development, 31, 197-224.

Sternberg, R. J. (1993). Sternberg Triarchic Abilities Test (Level H). (Unpublished test, Yale University). 
Sternberg, R. J. (1997). Thinking styles. New York: Cambridge University Press.

Sternberg, R. J. (1999). A triarchic approach to the understanding and assessment of intelligence in multicultural populations. Journal of School Psychology, 37, 145-159.

Sternberg, R. J., Castejón, J. L., Prieto, M. D., Hautamäki, J., \& Grigorenko, E. L. (2001). Confirmatory factor analysis of the Sternberg Triarchic Abilities Test in three international samples: An empirical test of the triarchic theory of intelligence. European Journal of Psychological Assessment, 17, 1-16.

Sternberg, R. J., \& Grigorenko, E. L. (1993). Thinking styles and the gifted. Roeper Review, 16, 122-130.

Sternberg, R. J., \& Grigorenko, E. L. (1995). Styles of thinking in the school. European Journal for High Ability, 6, 201-219.

Sternberg, R. J., Grigorenko, E. L., Ferrari, M., \& Clinkenbeard, P. (1999). A triarchic analysis of an aptitude-treatment interaction. European Journal of Psychological Assessment, 15, 1-11.

Sternberg, R. J., \& Wagner, R. K. (1992). Thinking Styles Inventory. (Unpublished test, Yale University).

Sternberg, R. J., \& Williams, W. M. (1997). Does the Graduate Record Examination predict meaningful success in the graduate training of psychologists? A case study. American Psychologist, 52, 630-641.

Thurstone, L. L. (1938). Primary mental abilities. Chicago: University of Chicago Press.

Torrance, E. P., McCarthy, B., \& Kolesinski, M. T. (1988). Style of learning and thinking. Bensenville, IL: Scholastic Testing Service.

Witkin, H. A. (1962). Psychological differentiation: Studies of development. New York: Wiley.

Yeatts, P. P., \& Strag, G. A. (1971). Flexibility of cognitive style and its relationship to academic achievement in fourth and sixth grades. Journal of Educational Research, 64, 345-346.

Yeung, L. (2003, May 3). Report slams teaching arts: Commission says classes "ill-suited to the 21 st century" and creativity is vital to pupils' development. South China Morning Post (Education Edition).

Yung, K. K. (1997). What happens to the attainment of our bottom $20 \%$ of students at the end of their nine-year compulsory education? Educational Research Journal, 12, $159-173$.

Zhang, L-F. (1999). Further cross-cultural validation of the theory of mental self-government. The Journal of Psychology, 133, 165-181.

Zhang, L-F. (2000a). Are thinking styles and personality types related? Educational Psy. chology, 20, 271-283.

Zhang, L-F. (2000b). Relationship between Thinking Styles Inventory and Study Process Questionnaire. Personality and Individual Differences, 29, 841-856.

Zhang, L-F. (2001a). Do styles of thinking matter among Hong Kong secondary school students? Personality and Individual Differences, 31, 289-301.

Zhang, L-F. (2001b). Do thinking styles contribute to academic achievement beyond abilities? The Journal of Psychology, 135, 621-637.

Zhang, L-F. (200lc). Thinking styles and personality types revisited. Personality and Individual Differences, 31, 883-894.

Zhang, L-F. (2001d). Thinking styles, self-esteem, and extracurricular experiences. International Journal of Psychology, 36, 100-107.

Zhang, L-F. (2002a). Measuring thinking styles in addition to measuring personality traits? Personality and Individual Differences, 33, 445-458.

Zhang, L-F. (2002b). The role of thinking styles in psychosocial development. Journal of College Student Development, 43, 696-711. 
Zhang, L-F. (2002c). Thinking styles and the Big Five Personality Traits. Educational Psychology, 22, 17-31.

Zhang, L-F. (2002d). Thinking styles and cognitive development. The Journal of Genetic Psychology, 163, 179-195.

Zhang, L-F. (2002e). Thinking styles and modes of thinking: Implications for education and research. The Journal of Psychology. 136, 245-261.

Zhang, L-F. (2002f). Thinking styles: Their relationships with modes of thinking and academic performance. Educational Psychology, 22, 331-348.

Zhang, L-F., \& Huang, J. F. (2001). Thinking styles and the five-factor model of personality. European Journal of Personality, 15, 465-476.

Zhang, L-F., \& Postiglione, G. A. (2001). Thinking styles, self-esteem, and socioeconomic status. Personality and Individual Differences, 31, 1333-1346.

Zhang, L-F., \& Sachs, J. (1997). Assessing thinking styles in the theory of mental selfgovernment: A Hong Kong validity study. Psychological Reports, 81, 915-928.

Zhang, L-F., \& Sternberg, R. J. (1998). Thinking styles, abilities, and academic achievement among Hong Kong university students. Educational Research Journal, 13, 41-62.

Zhang, L-F., \& Sternberg, R. J. (2000). Are learning approaches and thinking styles related? A study in two Chinese populations. The Journal of Psychology, 134, 469-489.

\section{APPENDIX \\ Thinking Styles in the Theory of Mental Self-Government}

Dimension Thinking style Key characteristics

\begin{tabular}{|c|c|c|}
\hline \multirow{3}{*}{ Function } & Legislative & $\begin{array}{l}\text { One prefers to work on tasks that require creative } \\
\text { strategies; one prefers to choose one's own } \\
\text { activities. }\end{array}$ \\
\hline & Executive & $\begin{array}{l}\text { One prefers to work on tasks with clear instructions } \\
\text { and structures; one prefers to implement tasks } \\
\text { with established guidelines. }\end{array}$ \\
\hline & Judicial & $\begin{array}{l}\text { One prefers to work on tasks that allow for one's } \\
\text { evaluation; one prefers to evaluate and judge the } \\
\text { performance of other people. }\end{array}$ \\
\hline \multirow{4}{*}{ Form } & Hierarchical & $\begin{array}{l}\text { One prefers to distribute attention to several tasks } \\
\text { that are prioritized according to one's valuing of } \\
\text { the tasks. }\end{array}$ \\
\hline & Monarchic & $\begin{array}{l}\text { One prefers to work on tasks that allow complete } \\
\text { focus on one thing at a time. }\end{array}$ \\
\hline & Oligarchic & $\begin{array}{l}\text { One prefers to work on multiple tasks in the service } \\
\text { of multiple objectives, without setting priorities. }\end{array}$ \\
\hline & Anarchic & $\begin{array}{l}\text { One prefers to work on tasks that would allow } \\
\text { flexibility as to what, where, when, and how } \\
\text { one works. }\end{array}$ \\
\hline
\end{tabular}




\section{APPENDIX (continued)}

\begin{tabular}{lll}
\hline Dimension & Thinking style & Key characteristics \\
\hline Level & Local & $\begin{array}{c}\text { One prefers to pay more attention to the overall } \\
\text { picture of an issue and to abstract ideas. } \\
\text { One prefers to work on tasks that require working } \\
\text { with concrete details. }\end{array}$ \\
\hline Scope & Enternal & $\begin{array}{c}\text { One prefers to work on tasks that allow one to work } \\
\text { as an independent unit. }\end{array}$ \\
& External & $\begin{array}{c}\text { One prefers to work on tasks that allow for } \\
\text { collaborative ventures with other people. }\end{array}$ \\
\hline Leaning & Conservative & $\begin{array}{c}\text { One prefers to work on tasks that involve novelty } \\
\text { and ambiguity. } \\
\text { One prefers to work on tasks that allow one to } \\
\text { adhere to the existing rules and procedures in } \\
\text { performing tasks. }\end{array}$ \\
\hline
\end{tabular}

Original manuscript received May 27, 2003

Final revision accepted December 9, 2003 